\title{
A discussion at the Philosophy Group's first residential conference
}

\author{
Mark G. A. Morris, c/o The Cassel Hospital, 1 Ham Common, Richmond, \\ Surrey TW10 7JF
}

Two theoretical positions in psychiatry, the psychodynamic and the biological are explored, as seen in a discussion at the conference mentioned. It is argued that they form part of a wider philosophical debate between idealism and materialism, which is explored with reference to ideas about substance and then using psychodynamic and biological theories of depression. Double aspect theory is presented as a pragmatic solution adopted by the profession.

At the first residential conference of the Royal College of Psychiatrists' Philosophy Group, a paper was presented on the state of research into the genetics of schizophrenia. A complex model of aetiology was proposed to take account of the various lines of evidence that have indicated that constitutional, psychodynamic and family environment all have a part to play. When the discussion was thrown open to the floor, one member said that in his opinion, when all was said and done, it would be found that the basic disorder in schizophrenia was about "choices" and relationships. Several delegates responded by quoting studies which in their view unequivocally indicated a biological basis to the illness. In spite of some strong feelings evoked, the discussion did not seem able to progress much further, as neither camp could engage the arguments of the opposition.

At the risk of over-generalisation, the two approaches to aetiology can be defined thus. Biological psychiatry sees psychiatric illness as brain dysfunction, and research and treatment are directed in this direction, whereas psychodynamic psychiatry looks more for psychological causes and meaning of illness, and treatment methods are based on the acquisition of insight into these. While most psychiatrists take an eclectic view of the causation of psychiatric illness which is reflected in the membership examination syllabus, in the past, there have been a few who take an extreme view. Psychodynamic psychiatry can be parodied as being a bit cranky and out of touch; biological psychiatry as rigid and narrow minded. I should like to suggest that the two opposing views are part of a fundamental debate running through the history of philosophy, between the traditions in the philosophy of metaphysics of materialism and idealism (Popkin, 1977). Neither the impasse in the argument nor the scorn of the extremists for those who hold the alternative view

is unique to the discipline of psychiatry, but is part of a long philosophical tradition (Russell, 1962, 1985).

\section{Materialism and idealism}

The materialist/idealist debate can be illustrated by reference to the development of ideas about the "substance" that makes up the universe. At the time when the physical sciences were at their infancy, philosophy provided the conceptual underpinning for scientific speculation and investigation. The idea of what the basic stuff of existence actually was preoccupied 17th century philosophers. Descartes' model proposed that there were two distinct substances (Descartes, 1983). His first is the material world, with hard solid objects able to be measured and whose existence and dimensions could be independently verified. The second substance was that of the mental world, with thoughts, images and consciousness, available only to the person thinking them. Physical objects obey the laws of Newtonian mechanics, whereas mental ones, thoughts and feelings, do not. Moving London Bridge to the United States would require considerable physical effort, but imagining it there requires almost none. This dual substance account has been very influential, although many philosophers were critical and aligned themselves on one or other side of the materialist/idealist divide.

An example of an idealist philosopher is Bishop Berkeley, who proposed that what is perceived as the material world is in fact an apparition created by God (Berkeley, 1985). The argument suggests that the only information about the existence of a physical world is in the form of ideas created by sensory information. There is no way to prove that the magazine you are holding exists other than by appeal to sensory information, you can see it or feel it, and so can others. Why, asks Berkeley, should God create a material universe when it is possible for him to achieve the same effect by orchestrating everybody's sensory perceptions to give the impression of the same thing? In contrast to this view was the materialism of Locke, who was more concerned with the "qualities in bodies" which produced such sensations as taste and colour (Locke, 1985). He proposed an underlying "substratum", which in some way "supported" these qualities, possibly consisting 
of tiny particles or atoms. Berkeley ridicules this concept. "How", he asks "as your legs support your body?" (Berkeley, 1985).

\section{Biological and psychodynamic psychiatry}

The biological and psychodynamic accounts of depression illustrate the conceptual differences between the two positions, and throws into relief the similarity between this debate and that between Locke and Berkeley. Biologically, a patient with a genetic predisposition becomes depressed "out of the blue". The depressive behaviour and vegetative symptoms are understood as being a result of disordered monoamine metabolism in specific neurone systems. Treatment is by manipulating the neuronal uptake of these neurotransmitters, so as to restore the normal physiological balance, when the symptoms will subside, and the person's normal personality and functioning will be restored. In this account no reference is made to ideas, the depression can be diagnosed, treated and understood as a purely physical, material phenomenon. A psychodynamic account might involve loss of a real or symbolic loved object, with any anger generated being introjected, or "turned in on the self" with the patient blaming himself for the loss, leading to self-depreciating thoughts and guilt. An appropriate therapy might be exploration of the loss and its meaning, and looking at any unresolved similar experiences in the past. The patient may come to acknowledge the rage, and leave the depressive spiral. The depression is treated and understood in the realm of ideas, and there might be no reference to the outside material world at all, in a manner reminiscent of Berkeley's account of things. The two accounts of depression are selfcontained and complete in themselves; they do not disagree so much as simply pass each other by, as they did in the discussion at the conference.

The everyday practice of psychiatry uses the two metaphysical theories together. In the clinic, for example, the mental state examination reveals ideas of wretchedness and guilt, the patient may have unfounded worries of poverty or impending disaster. With this information about the patient's ideas, a diagnosis of depression is made, and physical treatment is often prescribed, in the form of a drug, or electroconvulsive therapy. Why is treatment of the brain tissue prescribed for symptoms found in the mental sphere? How is one to explain the switch between diagnosing a syndrome of the patient's ideas, then physically treating his brain? Furthermore, how is it possible that this metaphysical muddle actually works, and patients improve? Psychiatry seems to have developed a metaphysics where the two accounts, material and ideal, operate in tandem and are used together. The closest philo- sophical theory to what seems to be practised in psychiatry is dual aspect theory (Vesey, 1968; Spinoza, 1955). This very simply suggests that both the materialist and the idealist versions of things are true, but that they look for things from different perspectives. Celebrated examples have been used to illustrate the principle; that a curve is both convex and concave at the same time; or that the morning star and the evening star are the same thing from different perspectives. Likewise, psychodynamic and biological accounts of depression are complementary, the psychodynamic in terms of the mind and its ideas; and the biological in terms of brain physiology. An account of depression requires the two aspects to be considered, or else the description is incomplete, in the same way as a curve needs to be fully described as both convex and concave.

The problem for psychiatry is that philosophically, dual aspect theory just won't do. Spinoza's original account used heavily the concept of God, of whom ideas and material things were different attributes (Spinoza, 1955). Vesey (1968) notes that the dual aspect idea assumes that the two aspects are presented to a somebody, a third aspect, so that the system collapses into absurdity. It would seem that the tentative psychiatric solution while pragmatically successful, remains philosophically flawed. The development of the Philosophy Group in the Royal College will mean that such debates will receive wider attention. According to Fish, "Before psychological problems can be discussed, it is necessary to realise the philosophical problems involved," even if, as in this case, the confusion is cleared to reveal a deeper and more fundamental philosophical problem.

\section{References}

Berkeley, G. (1985) Philosophical Works. London: J. M. Dent. Pp. 27-127.

DesCaRTES, R. (1983) The Essential Descartes (ed. M. G. Wilson). New York: New American Library. Pp. 264-227.

Fish, F. (1985) Fish's Clinical Psychopathology (ed. M. Hamilton). Bristol: John Wright. Pp. 1-7.

LOCKE, J. (1985) An Essay Concerning Human Understanding. (ed. J. W. Yolton). London: J. M. Dent. Pp. 131-150.

Popkin, R. H. \& Stroll, A. (1977) Philosophy. London: W. H. Allen. Pp 99-104.

Russell, B. (1962) Materialism, past and present. In The Basic Writings of Bertrand Russell (eds. R. E. Egner and L. E. Dennon). London: George Allen and Unwin. Pp. 236-245.

-, (1985) A History of Western Philosophy. London: Unwin Paperbacks. Pp. 542-551.

SPINOZA, B. (1955) On the Improvement of the Understanding; The Ethics; Correspondence. London: Constable. Pp. 45-81.

VESEY, G. (1982) Berkeley. Milton Keynes: Open University Press. p. 57.

-, (1968) Agent and Spectator. Royal Institute of Philosophy Lectures. London: Macmillan. 